\title{
Author Correction: BRD9 defines a SWI/SNF sub- complex and constitutes a specific vulnerability in malignant rhabdoid tumors
}

\author{
Xiaofeng Wang 1,2,7, Su Wang (10 3,7, Emma C. Troisi², Thomas P. Howard (1) 2,4, Jeffrey R. Haswell2, \\ Bennett K. Wolf ${ }^{1}$, William H. Hawk ${ }^{1}$, Pilar Ramos ${ }^{5}$, Elaine M. Oberlick ${ }^{2}$, Evgeni P. Tzvetkov ${ }^{2}$, Aaron Ross ${ }^{5}$, \\ Francisca Vazquez (10) ${ }^{4}$, William C. Hahn (10) ${ }^{4,6}$, Peter J. Park (D) ${ }^{3 \star} \&$ Charles W.M. Roberts ${ }^{2,5 \star}$
}

Correction to: Nature Communications https://doi.org/10.1038/s41467-019-09891-7, published online 23 April 2019.

The original version of this Article omitted the eleventh author Aaron Ross, who is from the 'Comprehensive Cancer Center and Department of Oncology, St. Jude Children's Research Hospital, Memphis, TN 38105, USA'. Consequently, the following was added to the Author contributions: 'A.R. performed experiments'. This has been corrected in both the PDF and HTML versions of the Article.

Published online: 26 September 2019

(c) Open Access This article is licensed under a Creative Commons Attribution 4.0 International License, which permits use, sharing, adaptation, distribution and reproduction in any medium or format, as long as you give appropriate credit to the original author(s) and the source, provide a link to the Creative Commons license, and indicate if changes were made. The images or other third party material in this article are included in the article's Creative Commons license, unless indicated otherwise in a credit line to the material. If material is not included in the article's Creative Commons license and your intended use is not permitted by statutory regulation or exceeds the permitted use, you will need to obtain permission directly from the copyright holder. To view a copy of this license, visit http://creativecommons.org/licenses/by/4.0/.

(C) The Author(s) 2019

\footnotetext{
${ }^{1}$ Department of Molecular and Systems Biology, Geisel School of Medicine, Dartmouth College, Hanover, NH 03756, USA. ${ }^{2}$ Department of Pediatric Oncology, Dana-Farber Cancer Institute, Boston, MA 02215, USA. ${ }^{3}$ Department of Biomedical Informatics, Harvard Medical School, Boston, MA 02115, USA. ${ }^{4}$ Broad Institute of Harvard and MIT, 415 Main Street, Cambridge, MA 02142, USA. ${ }^{5}$ Comprehensive Cancer Center and Department of Oncology, St. Jude Children's Research Hospital, Memphis, TN 38105, USA. ${ }^{6}$ Department of Medical Oncology, Dana-Farber Cancer Institute, Boston, MA 02215, USA. ${ }^{7}$ These authors contributed equally: Xiaofeng Wang, Su Wang. *email: peter_park@hms.harvard.edu; Charles.Roberts@STJUDE.ORG
} 